\title{
Refractory strictures despite steroid injection after esophageal endoscopic resection
}

Authors

Institution
Noboru Hanaoka, Ryu Ishihara, Noriya Uedo, Yoji Takeuchi, Koji Higashino, Tomofumi Akasaka, Takashi Kanesaka, Noriko Matsuura, Yasushi Yamasaki, Kenta Hamada, Hiroyasu lishi

Department of Gastrointestinal Oncology, Osaka Medical Center for Cancer and Cardiovascular Diseases, Osaka, Japan $\begin{array}{lll}\text { submitted } & 30 \text {. July } 2015\end{array}$ accepted after revision 4. January 2016

\section{Bibliography}

DOI http://dx.doi.org/

10.1055/s-0042-100903

Published online: 11.2.2016

Endoscopy International Open 2016; 04: E354-E359

(c) Georg Thieme Verlag KG Stuttgart · New York

E-ISSN 2196-9736

\section{Corresponding author}

\section{Noboru Hanaoka, MD}

Department of Gastrointestinal Oncology

Osaka Medical Center for

Cancer and Cardiovascular

Diseases

1-3-3 Nakamichi, Higashinari-ku Osaka 537-8511

Japan

Fax: +81-6-6981-4067

hanaoka-no@mc.pref.osaka.jp

\section{License terms}

(ㄱ)(1) $\ominus \circledast$
Background: Although steroid injection prevents stricture after esophageal endoscopic submucosal dissection (ESD), some patients require repeated sessions of endoscopic balloon dilation (EBD). We investigated the risk for refractory stricture despite the administration of steroid injections to prevent stricture in patients undergoing esophageal ESD. Refractory stricture was defined as the requirement for more than three sessions of EBD to resolve the stricture. In addition, the safety of steroid injections was assessed based on the rate of complications.

Patients and methods: We analyzed data from 127 consecutive patients who underwent esophageal ESD and had mucosal defects with a circumferential extent greater than three-quarters of the esophagus. To prevent stricture, steroid injection was performed. EBD was performed whenever a patient had symptoms of dysphagia.

\section{Introduction}

\section{$\nabla$}

Endoscopic submucosal dissection (ESD) can remove superficial esophageal cancers in an en bloc manner and allows precise histologic evaluation $[1,2]$. The indication for ESD in a patient with esophageal cancer is a tumor confined to the mucosa with a low risk for lymph node metastasis. The long-term outcome of endoscopic resection in patients with superficial esophageal cancer is excellent [3]. However, when larger lesions, such as semicircular lesions, are removed, there is a high risk for post-ESD esophageal stricture. The frequency of stricture after ESD for esophageal cancer in patients at high risk (mucosal defect of more than three-quarters of the circumference) is $70 \%$ to $90 \%$ [4-6]. Multivariate analysis has shown that a mucosal defect of more than threequarters of the circumference is a reliable predictor of stricture $[4,7,8]$.
Results: The percentage of patients with a tumor circumferential extent greater than $75 \%$ was significantly higher in those with refractory stricture than in those without stricture $(P=0.001)$. Multivariate analysis adjusted for age, sex, history of radiation therapy, tumor location, and tumor diameter showed that a tumor circumferential extent greater than $75 \%$ was an independent risk factor for refractory stricture (adjusted odds ratio [OR] 5.49 [95\%CI 1.91-15.84], $P=0.002$ ). Major adverse events occurred in 3 patients (2.4\%): perforation during EBD in 2 patients and delayed perforation after EBD in 1 patient. The patient with delayed perforation underwent esophagectomy because of mediastinitis.

Conclusions: A tumor circumferential extent greater than $75 \%$ is an independent risk factor for refractory stricture despite steroid injections. The development of more extensive interventions is warranted to prevent refractory stricture.

One of the prophylactic treatments for post-ESD stricture is oral systemic prednisolone or intralesional steroid injection. These methods can reduce the frequency of stricture $[5,6,9]$. Our team has administered multiple intralesional steroid injections in a single session immediately after ESD to effectively suppress inflammation. This method reduces the total dose of steroids and eliminates the need for additional endoscopic intervention after ESD. Although the frequency of stricture is reduced, some patients require repeated sessions of endoscopic balloon dilation (EBD) because of refractory stricture, and the risk for refractory stricture is unknown. Moreover, the safety of steroid injections has not been well evaluated. Therefore, we undertook this study to investigate the risk for refractory stricture after esophageal ESD despite the administration of steroid injections to prevent stricture in patients with a mucosal defect greater than three-quarters of the esophageal circumference. The safety of 
steroid injections was also investigated by assessing complications.

\section{Patients and methods}

\section{Patients}

Between September 2010 and February 2014, 370 consecutive patients with superficial esophageal cancer were treated by ESD. To prevent post-ESD stricture, triamcinolone was injected immediately after ESD in patients with a mucosal defect that involved more than three-quarters of the esophageal circumference. Therefore, these patients had a high risk for post-ESD stricture. The patient data were consecutively stored in a database and included tumor size, location, type, and histologic findings; operation time; and intraoperative and postoperative adverse events. We obtained permission to perform data analysis from the institutional review board of our hospital.

\section{Endoscopic submucosal dissection procedure}

The ESD procedure began with the patient under conscious anesthesia induced with an intravenous injection of midazolam and pentazocine hydrochloride. Additional midazolam was administered to maintain continuous sedation as needed throughout the procedure. All of the procedures were performed with an upper gastrointestinal endoscope (GIF-Q260J; Olympus, Tokyo, Japan) that was fitted with a transparent cap (D-201-11804; Olympus). A VIO 300 D Electrosurgical Generator (Erbe Electromedizin, Tübingen, Germany) was used as the electrosurgical generator unit. A $0.75 \%$ iodine solution was used to delineate the tumor margin, and marker dots were placed circumferentially outside the tumor margins with a flush knife (DK2618JN; Fujifilm Medical, Tokyo, Japan) or hook knife (KD-620LR; Olympus, Tokyo, Japan). The mucosal incision and submucosal dissection were performed with a flush knife, hook knife, or Mucosectom (DP-2518; Pentax, Tokyo, Japan). To lift the mucosa, $0.4 \%$ sodium hyaluronic acid (Mucoup; Johnson and Johnson K.K., Tokyo, Japan) was injected into the submucosa. Carbon dioxide insufflation was used during the procedure. Resected specimens were extended on a board with pins, fixed in $10 \%$ formalin for 24 hours, and sectioned at 2-mm intervals. Tumor size, invasion depth, lymphatic and vascular involvement, and tumor involvement of the lateral and vertical margins were assessed.

\section{Prevention of stricture}

A single session of intralesional steroid injections was undertaken immediately after ESD. Triamcinolone acetonide (Kenacort, $50 \mathrm{mg} / 5 \mathrm{~mL}$; Bristol-Meyers Squibb, Tokyo, Japan) was diluted 1:1 with saline to make a $5-\mathrm{mg} / \mathrm{mL}$ solution. A 25-gauge needle was used to inject the solution evenly into the residual submucosal tissue of the ulcer bed in 0.5 - to $1.0-\mathrm{mL}$ increments $(20-40$ punctures). The initial injections were performed at the margins of the ulcer, and then linear injections were performed from the distal to the proximal side of the ulcer margin ( $\bullet$ Video 1 ). If the muscle layer was partially exposed during ESD, steroid injections were not performed in that area to avoid possible muscle damage and delayed perforation. To effectively inject triamcinolone into the submucosal layer, submucosal dissection had to be performed at the middle level of the submucosal layer to create sufficient space. The amount of triamcinolone depended the size of the lesion and ranged from 50 to $100 \mathrm{mg}$. Systemic steroid administration was combined with local steroid injection in pa- tients who had a defect extending over the entire circumference because of the possibility that an extremely severe stricture could develop $[9,10]$. Oral prednisolone was given at $5 \mathrm{mg} / \mathrm{d}$ on the second day after ESD and was continued for 8 weeks.

\section{Follow-up and management of stricture}

Follow-up endoscopy was scheduled at 2 months after ESD unless a patient experienced dysphagia ( $\bullet$ Fig.1). EBD was performed when a patient experienced persistent dysphagia to solids. Stricture was defined as the presence of dysphagia with difficulty to some solids (dysphagia score of 2) or as the inability to pass an endoscope with a dimeter of $9.2 \mathrm{~mm}$ or larger ( $\bullet$ Fig. 2). EBD was performed by using a controlled radial expansion balloon (Boston Scientific, Marlborough, Massachusetts, USA). The size of the dilators that were used for the initial procedure varied from 12 to $15 \mathrm{~mm}$ according to the degree of the stricture. EBD was performed whenever a patient experienced dysphagia and was repeated on demand until the dysphagia resolved. Refractory stricture was defined as the requirement for more than three sessions of EBD to resolve the stricture. Perforation was diagnosed if mediastinal connective tissue was observed during the procedure. Mediastinal emphysema was diagnosed by the presence of air in the mediastinal space on plain radiography.

\section{Statistical analysis}

Categorical data were analyzed with the chi-squared test or Fischer's exact test, and numerical data were analyzed with Student's $t$ test. Multivariate logistic regression analysis was used to identify independent predictors of stricture. A $P$ value of less than 0.05 was considered significant. SPSS version 14.0 (SPSS, Chicago, Illinois, USA) was used for statistical analysis.

\section{Results}

\section{$\nabla$}

A total of 134 consecutive patients with superficial esophageal cancer and a mucosal defect extending over more than threequarters of the circumference of the esophagus received steroid therapy to prevent post-ESD stricture. Of these, two patients

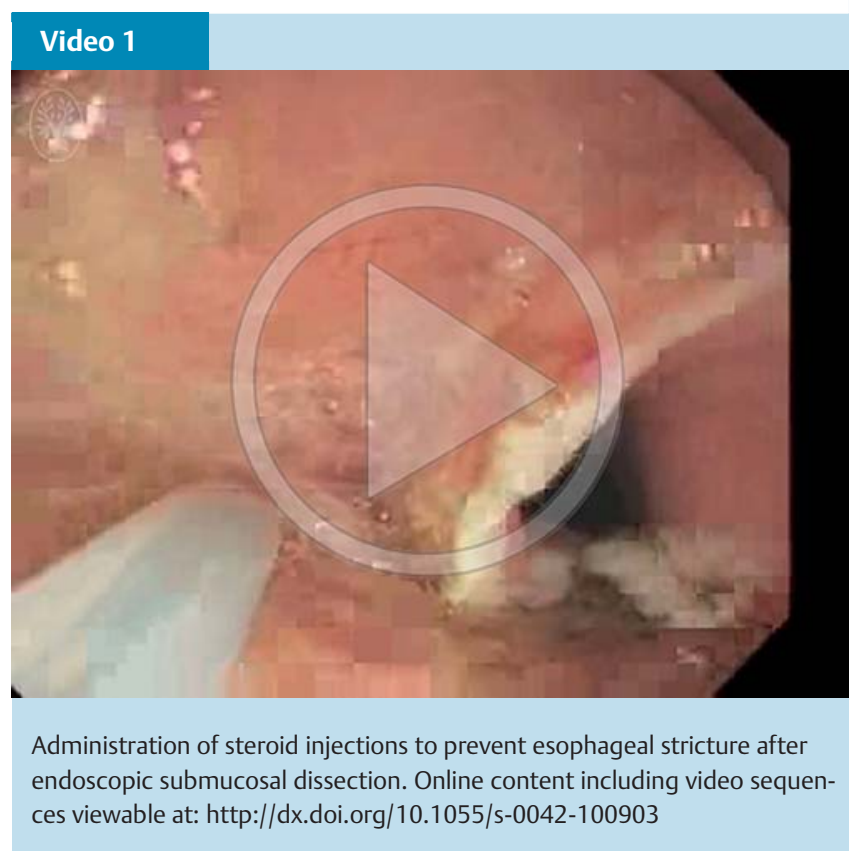




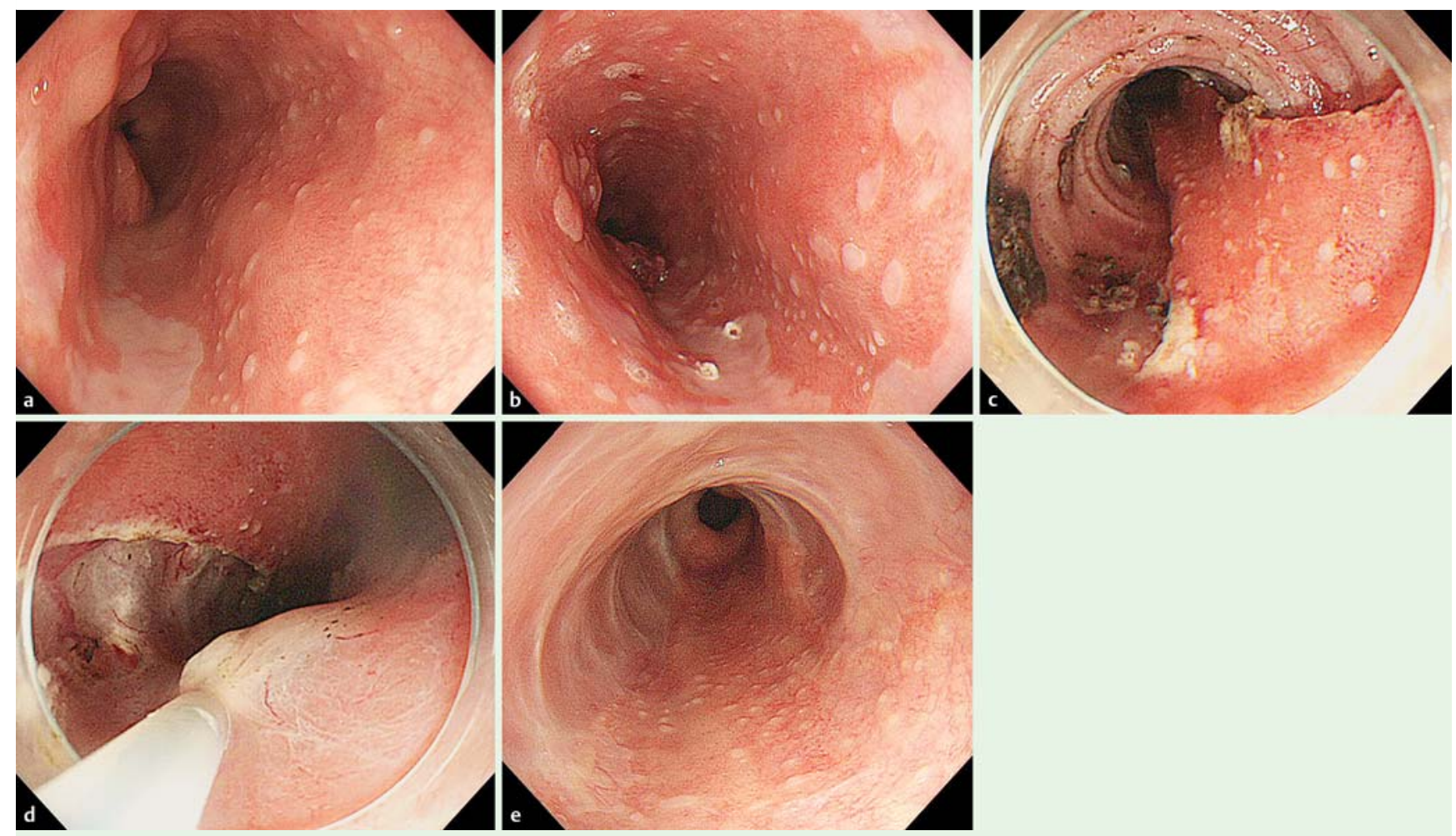

Fig. 1 a Superficial Barrett's cancer in the lower thoracic esophagus. Circumferential tumor extent ranges from $50 \%$ to $75 \%$. b Marker dots are placed along the tumor margin. c Artificial ulcer after endoscopic submucosal dissection (ESD). $\mathbf{d}$ Triamcinolone is injected into the submucosal layer immediately after ESD. e No stricture has developed at 2 months after ESD.

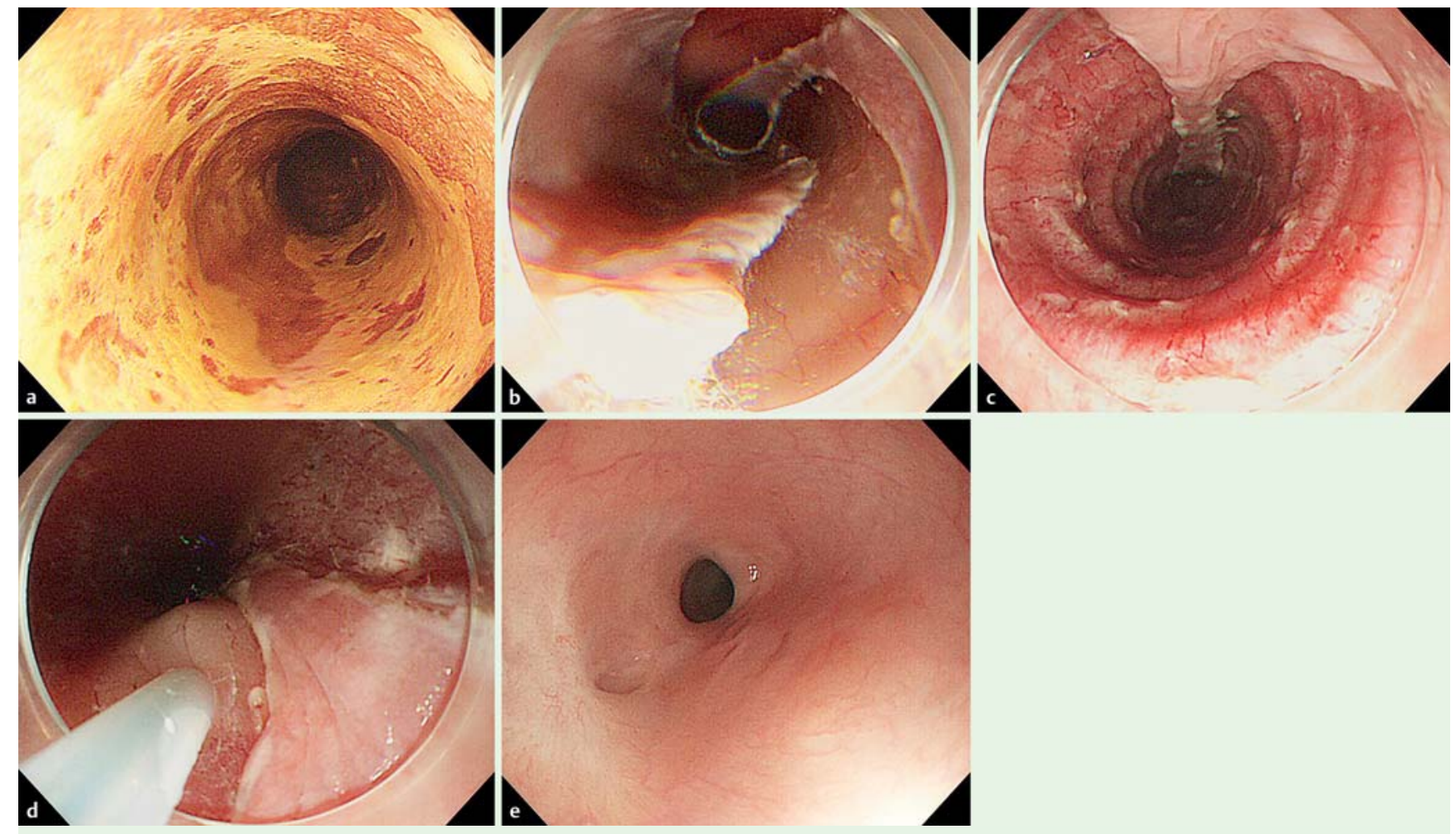

Fig. 2 a Superficial esophageal cancer in the upper thoracic esophagus. Circumferential tumor extent is greater than $75 \%$. b Semicircular dissection during endoscopic submucosal dissection (ESD). c Artificial ulcer after ESD. d Triamcinolone is injected into the submucosal layer immediately after ESD. e Stricture has developed at 2 months after ESD. 


\begin{tabular}{|c|c|c|c|}
\hline & \multicolumn{3}{|c|}{ Refractory stricture } \\
\hline & $(+)(n=24)$ & $(-)(n=103)$ & $P$ value \\
\hline Age, mean $\pm S D, y$ & $68 \pm 8$ & $67 \pm 8$ & 0.438 \\
\hline Sex, male/female, $n$ & $22 / 2$ & $90 / 13$ & 0.558 \\
\hline Tumor location, $n$ & & & 0.254 \\
\hline $\mathrm{Ce}$ & 2 & 2 & \\
\hline Ut, Mt, Lt & 21 & 98 & \\
\hline EG] & 1 & 3 & \\
\hline Depth of invasion, $n$ & & & 0.838 \\
\hline T1a & 20 & 84 & \\
\hline T1b & 4 & 19 & \\
\hline Muscle exposure, $n$ & 5 & 22 & 0.995 \\
\hline History of radiation therapy, $\mathrm{n}$ & 1 & 7 & 0.633 \\
\hline Tumor circumferential extent, $\mathrm{n}$ & & & 0.001 \\
\hline$>1 / 2, \leq 3 / 4$ & 6 & 63 & \\
\hline$>3 / 4$ & 18 & 40 & \\
\hline Tumor diameter, $\mathrm{n}$ & & & 0.561 \\
\hline$\leq 40 \mathrm{~mm}$ & 5 & 21 & \\
\hline$\leq 50 \mathrm{~mm}$ & 6 & 37 & \\
\hline$>50 \mathrm{~mm}$ & 13 & 45 & \\
\hline EBD sessions, median (range), $n$ & $7(3-40)$ & $0(0-2)$ & $<0.001$ \\
\hline
\end{tabular}

Table 1 Characteristics of patients and lesions in a study of risk factors for esophageal stricture following endoscopic submucosal dissection.

SD, standard deviation; Ce, cervical esophagus; Ut, upper thoracic; Mt, middle thoracic; Lt, lower thoracic; EG], esophagogastric junction; EBD, endoscopic balloon dilation.

Table 2 Predictors of risk for refractory stricture despite preventive steroid injection after endoscopic submucosal dissection.

\begin{tabular}{|lll}
\hline Tumor circumferential extent & Adjusted OR $(\mathbf{9 5} \% \mathbf{C l})^{\mathbf{1}}$ & $\boldsymbol{P}$ value \\
\hline$>1 / 2, \leq 3 / 4$ & Reference & \\
\hline$>3 / 4$ & $5.49(1.91-15.84)$ & 0.002 \\
\hline
\end{tabular}

$\mathrm{OR}$, odds ratio; $\mathrm{Cl}$, confidence interval.

${ }^{1}$ Adjusted for age, sex, history of radiation therapy, location of tumor, and tumor diameter.

were excluded because they underwent additional surgery after ESD, two because they were followed at another hospital, and three because they had a history of subtotal esophagectomy. The remaining 127 patients were included in the analysis. En bloc resection was achieved in all of the patients. The clinicopathologic features of the patients are shown in $\bullet$ Table 1. The percentage of patients with a tumor circumferential extent greater than $75 \%$ was significantly higher in those with refractory stricture than in those without stricture $(P=0.001)$. Multivariate analysis adjusted for age, sex, history of radiation therapy, tumor location, and tumor diameter showed that a tumor circumferential extent greater than $75 \%$ was an independent risk factor for refractory stricture (adjusted OR 5.49 [95\%CI $1.91-15.84$ ], $P=0.002$ ) ( $\square$ Table 2).

In subgroup analysis, resection of the whole circumference was performed in 12 patients, stricture occurred in 11 patients, and the median number of EBD sessions required to resolve stricture was 13 (range $0-40$ ). When the patients were stratified in two subgroups - whole circumferential resection and semicircular resection - multivariate analysis adjusted for age, sex, history of radiation therapy, tumor location, and tumor diameter showed that a whole circumferential resection was an independent risk factor for refractory stricture (adjusted OR 19.77 [95\%CI 4.67-83.72], $P<0.001$ ).

Major adverse events occurred in 3 of the 127 patients (2.4\%): perforation during the procedure in 2 patients and delayed perforation after EBD in 1 patient ( Table 3 ). The patient with delayed perforation (case 3 ) underwent esophagectomy. He was a 60-year-old man in whom dysphagia developed 1 month after ESD. Initial EBD was successful, and a steroid (total amount of $100 \mathrm{mg}$ of triamcinolone) was injected at the submucosal tear to avoid re-stricture. At 24 hours after EBD, the patient had chest pain and fever, and esophageal perforation was diagnosed by esophagogastroduodenoscopy. In addition, pneumomediastinum and periesophageal fluid collection were revealed by computed tomography. In the other patients with perforation, the perforation was diagnosed soon after EBD, and they were treated conservatively with fasting and antibiotics.

\section{Discussion}

We previously reported that intralesional steroid injection immediately after ESD was effective in preventing post-ESD stricture [6]. However, refractory stricture occurred in some patients, despite their having received steroid injections. In the current

Table 3 Adverse events related to endoscopic balloon dilation.

\begin{tabular}{|c|c|c|c|c|c|c|c|c|}
\hline $\begin{array}{l}\text { Case } \\
\text { No. }\end{array}$ & Event & Age/sex & $\begin{array}{l}\text { Tumor } \\
\text { location }\end{array}$ & $\begin{array}{l}\text { Depth of } \\
\text { invasion }\end{array}$ & $\begin{array}{l}\text { History } \\
\text { of RT }\end{array}$ & $\begin{array}{l}\text { Tumor circumferen- } \\
\text { tial extent }\end{array}$ & $\begin{array}{l}\text { Tumor di- } \\
\text { ameter, mm }\end{array}$ & $\begin{array}{l}\text { EBDs before } \\
\text { event, } n\end{array}$ \\
\hline 1 & Perforation & $76 / M$ & $\mathrm{Lt}$ & LP & No & $>1 / 2, \leq 3 / 4$ & 35 & 1 \\
\hline 2 & Perforation & $69 / M$ & Mt & LP & No & $>3 / 4$ & 50 & 0 \\
\hline 3 & Delayed perforation & $60 / \mathrm{M}$ & Mt & LP & No & $>3 / 4$ & 50 & 0 \\
\hline
\end{tabular}

RT, radiation therapy; EBD, endoscopic balloon dilation; Lt, lower thoracic; Mt, middle thoracic; LP, lamina propria. 
study, we found that a tumor circumferential extent greater than $75 \%$ was an independent risk factor for refractory stricture. A tumor location in the cervical esophagus is thought to be a risk factor for refractory stricture after ESD because of the variation in the esophageal luminal diameter, which is smaller in the upper esophagus than in the lower esophagus [8]. In our study, a tumor location in the cervical esophagus tended to be associated with refractory stricture. One of the reasons that this has not been confirmed as a significant risk factor for refractory stricture is because of the small number of patients who undergo ESD in the cervical esophagus. Radiation therapy of the esophagus is thought to be a risk factor for refractory stricture because radiation itself carries a risk for stricture [11]. In addition, it is difficult to inject steroids into the submucosal layer owing to post-radiation scar formation. However, an association between radiation therapy and refractory stricture has not been found.

The injection or oral administration of steroids to prevent stricture has been reported $[5,6,9]$. Scar formation is thought to be an integral part of wound healing, a process that involves inflammation, proliferation, and remodeling. Collagen is the major fibrous connective tissue protein and provides structural support in scars [12]. Steroids have been shown to attenuate the inflammatory process, reducing collagen and glycosaminoglycan synthesis as well as fibroblast proliferation, and promoting fibroblast degeneration and inhibition of growth [13]. The advantage of steroid injection over oral administration is the lower risk for adverse events. This is because the total amount of steroids is smaller and their effects are limited to the submucosal layer when they are injected rather than administered systemically by the oral route. In view of the initial daily dose of $30 \mathrm{mg}$ and total dose of $1000 \mathrm{mg}$ of prednisolone with this method, the potential risk for prednisolone-related adverse events, such as infection and diabetes mellitus, should be considered [14]. To reduce the total dose of steroids, Kataoka et al. developed short-period and low-dose steroid therapy, which was a modification of the original method of oral prednisolone therapy [15]. With their method, in which steroid therapy was administered for 3 weeks and the total steroid dose was $420 \mathrm{mg}$, the rate of stricture was reduced [15].

One of the disadvantages of steroid injection is the risk for delayed perforation [16]. If a steroid is injected into the muscle layer or deeper, the wall of the esophagus may become fragile. This leads to perforation because of the infiltration of inflammatory and granulation cells and insufficient fibrosis in the esophageal wall [17].

In our study, adverse events occurred in 3 patients: perforation in 2 patients and delayed perforation in 1 patient. The frequency of perforation related to EBD per patient was 5.9\%(2/34). This result is similar to that in a previous report of esophageal perforation, $9.2 \%(7 / 76)$, in patients who received EBD for the treatment of esophageal strictures [18]. In our study, all of the adverse events occurred within 1 month. Adverse events occurred during initial EBD in 3 patients. Therefore, caution is required during initial EBD within 1 month after ESD followed by steroid injection because the wall of the esophagus may be fragile. The esophageal wall contains transmural inflammatory granulation tissue, with disruption of the proper muscle layer and the presence of inflammatory necrotic tissue on the surface of the ulcer bed, as shown in a porcine model [17].

Temporary stent placement is a treatment option to avoid stricture. Saito et al. reported biodegradable stent insertion in 7 patients within 2 to 3 days after ESD [19]. Some of the stents were effective for preventing stricture, but spontaneous migration occurred between 10 and 21 days after placement. Although migrated stents are excreted with feces, the risk for gastrointestinal obstruction due to stent migration cannot be ignored.

Recently, another new method of preventing stricture was developed. In this sheet-shielding method, sheets of autologous cells collected from oral mucosal epithelium [20] or polyglycolic acid sheets (Neoveil; Gunze Co., Kyoto, Japan) with fibrin glue (Beriplast P 3-mL Combi-Set; CSL Behring Pharma, Tokyo, Japan) are endoscopically transplanted $[21,22]$. These methods appear to be promising because they are less invasive than steroid therapy and are expected to prevent post-ESD stricture. However, they are associated with problems of cost-effectiveness and technical difficulties involving sheet delivery systems.

This study has some limitations. It was retrospective. Additionally, the sample size was relatively small, which could have resulted in our failure to identify some other factors related to refractory stricture.

In conclusion, our data suggest that a tumor circumferential extent greater than $75 \%$ is an independent risk factor for refractory stricture despite steroid injection. To prevent refractory stricture, the development of more extensive interventions, such as injections with systemic steroids, a tissue-shielding method, and stent insertion, is warranted. In addition, the safety of steroid injections or EBD in patients with refractory stricture should be evaluated in a large number of cases.

\section{Competing interests: None}

\section{References}

1 Oyama T, Tomori A, Hotta $K$ et al. Endoscopic submucosal dissection of early esophageal cancer. Clin Gastroenterol Hepatol 2005; 3: S67-S70

2 Ishihara $R$, Iishi $H$, Uedo $N$ et al. Comparison of EMR and endoscopic submucosal dissection for en bloc resection of early esophageal cancers in Japan. Gastrointest Endosc 2008; 68: 1066 - 1072

3 Yamashina T, Ishihara R, Nagai $\mathrm{K}$ et al. Long-term outcome and metastatic risk after endoscopic resection of superficial esophageal squamous cell carcinoma. Am J Gastroenterol 2013; 108: 544-551

4 Katada C, Muto M, Manabe T et al. Esophageal stenosis after endoscopic mucosal resection of superficial esophageal lesions. Gastrointest Endosc 2003; 57: 165-169

5 Hashimoto S, Kobayashi M, Takeuchi M et al. The efficacy of endoscopic triamcinolone injection for the prevention of esophageal stricture after endoscopic submucosal dissection. Gastrointest Endosc 2011; 74: $1389-1393$

6 Hanaoka $N$, Ishihara $R$, Takeuchi $Y$ et al. Intralesional steroid injection to prevent stricture after endoscopic submucosal dissection for esophageal cancer: a controlled prospective study. Endoscopy 2012; 44: $1007-1011$

7 Ono S, Fujishiro M, Niimi K et al. Predictors of postoperative stricture after esophageal endoscopic submucosal dissection for superficial squamous cell neoplasms. Endoscopy 2009; 41: 661-665

8 Mizuta H, Nishimoril I, Kuratani Y et al. Predictive factors for esophageal stenosis after endoscopic submucosal dissection for superficial esophageal cancer. Dis Esophagus 2009; 22: 626-631

9 Yamaguchi $N$, Isomoto H, Nakayama T et al. Usefulness of oral prednisolone in the treatment of esophageal stricture after endoscopic submucosal dissection for superficial esophageal squamous cell carcinoma. Gastrointest Endosc 2011; 73: 1115-1121

10 Isomoto H, Yamaguchi N, Nakayama T et al. Management of esophageal stricture after complete circular endoscopic submucosal dissection for superficial esophageal squamous cell carcinoma. BMC Gastroenterol 2011; $11: 46$

11 Agarwalla A, Small AJ, Mendelson AH et al. Risk of recurrent or refractory strictures and outcome of endoscopic dilation for radiation-induced esophageal strictures. Surg Endosc 2015; 29: 1903-1912

12 Ramage JI Jr, Rumalla A, Baron TH et al. A prospective, randomized, double-blind, placebo-controlled trial of endoscopic steroid injection 
therapy for recalcitrant esophageal peptic strictures. Am J Gastroenterol 2005; 100: 2419-2425

13 Jalali $M$, Bayat A. Current use of steroids in management of abnormal raised skin scars. Surgeon 2007; 5: 175-180

14 Ishida T, Morita Y, Hoshi N et al. Disseminated nocardiosis during systemic steroid therapy for the prevention of esophageal stricture after endoscopic submucosal dissection. Dig Endosc 2015; 27: 388 - 391

15 Kataoka M, Anzai S, Shirasaki T et al. Efficacy of short period, low dose oral prednisolone for the prevention of stricture after circumferential endoscopic submucosal dissection (ESD) for esophageal cancer. Endosc Int Open 2015; 3: E113-E117

16 Oyama T. Prevention of stricture after large esophageal endoscopic submucosal dissections. Endoscopy 2015; 47: 289-290

17 Nonaka K, Miyazawa M, Ban S et al. Different healing process of esophageal large mucosal defects by endoscopic mucosal dissection between with and without steroid injection in an animal model. BMC Gastroenterol 2013; 13: 72
18 Takahashi H, Arimura Y, Okahara S et al. Risk of perforation during dilation for esophageal strictures after endoscopic resection in patients with early squamous cell carcinoma. Endoscopy 2011; 43: 184-189

19 Saito $Y$, Tanaka T, Andoh A et al. Usefulness of biodegradable stents constructed of poly-l-lactic acid monofilaments in patients with benign esophageal stenosis. World J Gastroenterol 2007; 13: 3977 - 3980

20 Ohki T, Yamato M, Ota $M$ et al. Prevention of esophageal stricture after endoscopic submucosal dissection using tissue-engineered cell sheets. Gastroenterology 2012; 143: 582 -588

21 Iizuka T, Kikuchi D, Yamada A et al. Polyglycolic acid sheet application to prevent esophageal stricture after endoscopic submucosal dissection for esophageal squamous cell carcinoma. Endoscopy 2015; 47: $341-344$

22 Sakaguchi Y, Tsuji Y, Ano S et al. Polyglycolic acid sheets with fibrin glue can prevent esophageal stricture after endoscopic submucosal dissection. Endoscopy 2015; 47: 336-340 